\title{
Application of Glycyrrhiza glabra Root as a Novel Adsorbent in the Removal of Toluene Vapors: Equilibrium, Kinetic, and Thermodynamic Study
}

\author{
Fazel Mohammadi-Moghadam, ${ }^{1,2,3}$ Mohammad Mehdi Amin, ${ }^{1,2}$ \\ Mehdi Khiadani (Hajian), ${ }^{1,4}$ Fariborz Momenbeik, ${ }^{5}$ Heshmatollah Nourmoradi, ${ }^{6}$ \\ and Mohammad Sadegh Hatamipour ${ }^{7}$ \\ ${ }^{1}$ Environment Research Center, Isfahan University of Medical Sciences (IUMS), Isfahan, Iran \\ ${ }^{2}$ Department of Environmental Health Engineering, School of Health, IUMS, Isfahan, Iran \\ ${ }^{3}$ Department of Environmental Health Engineering, School of Health, Shahrekord University of Medical Sciences, Shahrekord, Iran \\ ${ }^{4}$ School of Engineering, Edith Cowan University, WA 6027, Australia \\ ${ }^{5}$ Department of Chemistry, Faculty of Sciences, University of Isfahan, Isfahan, Iran \\ ${ }^{6}$ Department of Environmental Health Engineering, School of Health, Ilam University of Medical Sciences, Ilam, Iran \\ ${ }^{7}$ Department of Chemical Engineering, Faculty of Engineering, University of Isfahan, Hezar Jerib Avenue, Isfahan 81746-73441, Iran
}

Correspondence should be addressed to Mohammad Sadegh Hatamipour; hatami@eng.ui.ac.ir

Received 21 January 2013; Accepted 9 February 2013

Academic Editor: Roya Kelishadi

Copyright (c) 2013 Fazel Mohammadi-Moghadam et al. This is an open access article distributed under the Creative Commons Attribution License, which permits unrestricted use, distribution, and reproduction in any medium, provided the original work is properly cited.

\begin{abstract}
The aim of this paper is to investigate the removal of toluene from gaseous solution through Glycyrrhiza glabra root (GGR) as a waste material. The batch adsorption experiments were conducted at various conditions including contact time, adsorbate concentration, humidity, and temperature. The adsorption capacity was increased by raising the sorbent humidity up to 50 percent. The adsorption of toluene was also increased over contact time by $12 \mathrm{~h}$ when the sorbent was saturated. The pseudo-second-order kinetic model and Freundlich model fitted the adsorption data better than other kinetic and isotherm models, respectively. The Dubinin-Radushkevich (D-R) isotherm also showed that the sorption by GGR was physical in nature. The results of the thermodynamic analysis illustrated that the adsorption process is exothermic. GGR as a novel adsorbent has not previously been used for the adsorption of pollutants.
\end{abstract}

\section{Introduction}

Environmental pollution, as a result of industrial improvements, has created severe problems in the recent years. Volatile organic compounds (VOCs) are the major pollutants being released from various industrial plants and processes [1-4]. Some VOCs such as toluene existing in fuels, petroleum, and gasoline are widely used in many industrial solvents $[5,6]$. Toluene vapors are released into the atmospheric environment over their production, transportation, application, and discharge every year [2]. Toluene can be absorbed by respiratory and gastrointestinal tracts. The human exposure to toluene results in neurotoxicity, mental depression, and various symptoms such as headache, fatigue and ataxia [7]. The US Environmental Protection Agency (USEPA) has considered toluene as a major pollutant, the concentration of which must be reduced to a very low level in the environment [8-10]. Various techniques including biofilter, biotrickling filter, bioscrubber, and adsorption have been successfully adopted to remove toluene vapors from gaseous media [1, 11-14].

Many adsorbents including zeolites [15-18], metal oxides [19], compost [11, 20], diatomaceous earth, chaff [20], ground tire rubber [11], and activated carbon [21-26] have been used for the removal of toluene vapors. Among the abovementioned adsorbents, adsorption by activated carbon is one 
of the most common processes to remove VOCs, especially toluene, from gases solution, but, it is not cost effective [7]. Glycyrrhiza glabra is a herb that grows in various parts of the world as well as the southern areas of Iran [27]. It is a very sweet, humid, and soothing plant which has been used as a medicine to protect the liver, and to treat arthritis and the mouth ulcers for centuries in European and Eastern countries [27, 28]. The roots of Glycyrrhiza glabra are thick, long, cylindrical, fibrous, and multibranched [27] which after using its extract for medicine are disposed. In this study, the waste roots were, as a novel sorbent, used to remove toluene from gaseous solution. The main purpose of this study was to investigate the effect of various conditions including humidity, contact time, adsorbate concentration, and temperature on the adsorption of toluene vapor.

Literature review did not show any previous research using GGR waste as pollutant adsorbent. Only in a study, GGR was used as carbon sources in biological denitrification of drinking water [29].

\section{Materials and Methods}

2.1. Preparation of the Adsorbent. Glycyrrhiza glabra root (GGR) was provided by Rishmak Inc., an extract producing company located in Shiraz, Iran. The root of the herb was extracted at 3.5 bar pressure and $140^{\circ} \mathrm{C}$ temperature for 2 hours. Then dewatered GGR is dumped around the company as a waste material. In this paper, the GGR was ground to pieces of $0.5-1 \mathrm{~cm}$, repeatedly washed with deionized water, dried in oven at $60^{\circ} \mathrm{C}$ for $48 \mathrm{~h}$, and sterilized at $15 \mathrm{psi}$ for 20 min.

2.2. Instrument. The surface area of GGR was determined with a multipoint $\mathrm{N}_{2}$ gas adsorption method (Sorptometer Kelvin 1042, Costech International, Italy). The chemical composition of the adsorbent was also characterized by Xray fluorescence analyzer (Bruker, S4, Pioneer, Germany) and elemental combustion system (ECS 4010, Costech International, Italy). The concentration of toluene (purity of $99.5 \%$, Merck, Germany) in the solution was quantified by a gas chromatography equipped with flame ionization detector (Agilent GC, 7890A, Netherland). The GC-FID procedure was optimized as follows.

The amount of $100 \mu \mathrm{L}$ of gaseous sample was injected into the instrument by $1 \mathrm{~mL}$ gastight syringes (Hamilton series no. 1001; Hamilton Co., NV, USA) equipped with Teflon Minnert fittings.

Helium (with flow rate of $1.11 \mathrm{~mL} / \mathrm{min}$ ) and $\mathrm{H}_{2}$ (with flow rate of $30 \mathrm{~mL} / \mathrm{min}$ ) were used as carrier gas and fuel gas, respectively. The characteristic of GC column was Agilent CP Sil 5: $30 \mathrm{~m} \times 250 \mu \mathrm{m} \times 0.25 \mu \mathrm{m}$. The temperatures of the oven, injector, and detector were fixed at 100,230 , and $250^{\circ} \mathrm{C}$, respectively.

The $\mathrm{pH}$ value and the particle size analyses of GGR were measured by digital $\mathrm{pH}$ meter and sieves with standard mesh, respectively. The bulk density and the water holding capacity analysis of adsorbent was conducted according to Ahn et al. [30].
2.3. Adsorption Experiments. The experiments including adsorbent humidity (0-70\%), contact time (0-24h), and adsorbate concentration $(6.928 \mathrm{mg} / \mathrm{L})$ were carried out at room temperature $\left(25^{\circ} \mathrm{C}\right.$ ) in the $250 \mathrm{~mL}$ vials (with PTFE airtight cap) and mixed by a rotary shaker ( $300 \mathrm{rpm}$ for $24 \mathrm{~h}$ ). The effect of temperature $\left(10-50^{\circ} \mathrm{C}\right)$ on the adsorption was also determined as described above. After agitation period, $100 \mu \mathrm{L}$ of the polluted gas was analyzed for toluene by GCFID. All the experiments were performed in triplicates and the mean values were considered. Blank samples were also employed to determine the amount of toluene loss. The blank recoveries ranged from 93.8 to $96 \%$ and the experimental data were adjusted for these recoveries. Calibration curve for determination of the toluene concentration was prepared according to the standard method [31]. by

The adsorbent capacity of GGR for toluene was calculated

$$
q_{e}=\frac{\left(C_{0}-C_{e}\right) V}{m}
$$

where $q_{e}(\mathrm{mg} / \mathrm{g})$ is the adsorption capacity of GGR, $C_{0}$ $(\mathrm{mg} / \mathrm{L})$ is the initial concentration of toluene, $C_{e}(\mathrm{mg} / \mathrm{L})$ is the equilibrium concentration of the toluene in the solution, $m(\mathrm{~g})$ is the mass of the adsorbent, and $V(\mathrm{~L})$ is the volume of the polluted gas (or volume of the vial).

\section{Results and Discussion}

3.1. Characterization of Media. The physical and chemical characteristics of GGR are presented in Table 1.

3.2. The Effect of Adsorbent Humidity. The effect of adsorbent humidity $(0-70 \%)$ on the sorption was determined. As can be seen in Figure 1, the adsorption capacity was expanded by increasing the sorbent humidity up to 50 percent. The sorbent humidity higher than $50 \%$ may be due to the occupation of the media porosity by water content, leading to the reduction of the adsorption capacity. Acuña et al. (2000) found out that the variation of water content of peat as an adsorbent for the toluene vapors did not have significant effects on the sorption rate [32]. GGR with a humidity of 50 percent was used for the subsequent experiments.

3.3. The Effect of Contact Time. Figure 2(a) shows the effect of contact time $(0-24 \mathrm{~h})$ on the adsorption of toluene by GGR. The adsorption as can be seen in the figure reached its maximum capacity by the elapse of time.

The adsorption of toluene was quickly increased over the first hour of the sorption $(1.3 \mathrm{mg} / \mathrm{g})$ and steadily raised over the remaining contact time by $12 \mathrm{~h}$ since the adsorption sites are more accessible at the beginning of the sorption process and diminished by the passage of time. The contact time of $12 \mathrm{~h}$ was chosen for the rest of experiments. The adsorption capacity $\left(q_{e}\right)$ of GGR for the removal of toluene vapor was $2.2 \mathrm{mg} / \mathrm{g}$ over the $12 \mathrm{~h}$ contact time. Table 2 compares the adsorption capacity of granular activated carbon (GAC), compost, diatomaceous earth, chaff, ground tire rubber (GTR), and GGR. The use of activated carbon may be 
TABLE 1: Characteristics of the GGR (on the dry basis).

\begin{tabular}{lc}
\hline Parameters & \\
\hline Chemical composition (\%) & 4.83 \\
$\mathrm{CaO}$ & 1.76 \\
$\mathrm{SiO}_{2}$ & 0.552 \\
$\mathrm{Al}_{2} \mathrm{O}_{3}$ & 0.317 \\
$\mathrm{Fe}_{2} \mathrm{O}_{3}$ & 0.243 \\
$\mathrm{SO}_{3}$ & 0.186 \\
$\mathrm{MgO}_{\mathrm{Na}} \mathrm{O}$ & 0.072 \\
$\mathrm{~K}_{2} \mathrm{O}$ & 0.068 \\
$\mathrm{P}_{2} \mathrm{O}_{5}$ & 0.062 \\
$\mathrm{SrO}$ & 0.046 \\
$\mathrm{Cl}$ & 0.030 \\
$\mathrm{ZnO}$ & 0.019 \\
$\mathrm{TiO}$ & \\
$\mathrm{CuO}$ & 0.017 \\
$\mathrm{C}$ & 0.011 \\
$\mathrm{H}$ & 44.6 \\
$\mathrm{~N}$ & 5.33 \\
$\mathrm{Physical}$ characteristics & 1.47 \\
\hline $\mathrm{pH}$ & \\
$\mathrm{BET}$ surface area $\left(\mathrm{m}^{2} / \mathrm{g}\right)$ & 7.4 \\
$\mathrm{Particle}$ diameter $(\mathrm{cm})$ & 1.532 \\
Water holding capacity $(\mathrm{g}$ water/g dry GGR) & $0.5-1$ \\
$\mathrm{Bulk}$ density $\left(\mathrm{kg} / \mathrm{m}^{3}\right)$ & 2.9 \\
\hline
\end{tabular}

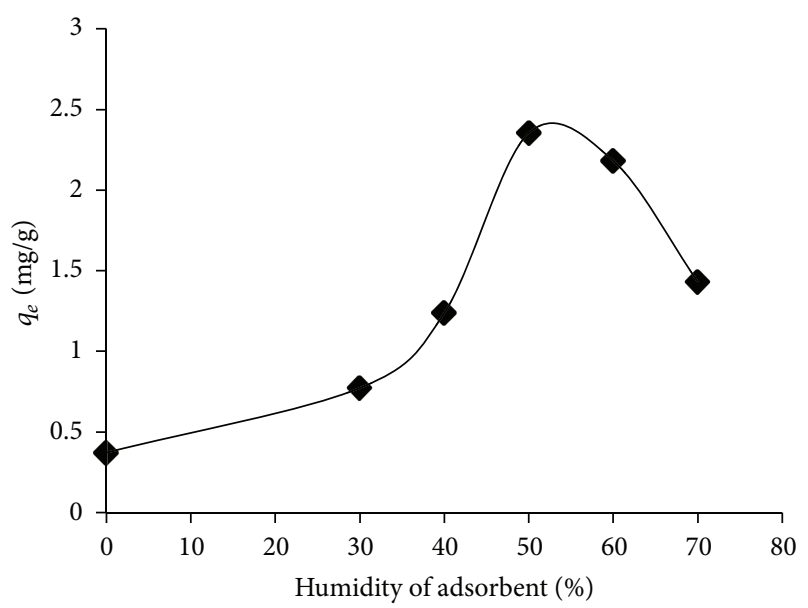

FIGURE 1: The effect of humidity of media on the sorption of toluene (adsorbent dose $=0.6 \mathrm{~g}$, temperature $=25^{\circ} \mathrm{C}$, contact time $=24 \mathrm{~h}$, and adsorbate conc. $=6.928 \mathrm{mg} / \mathrm{L}$ ).

prohibitive due to its high cost. The capacity of GGR in the removal of toluene is higher than the other natural adsorbents (e.g., compost, diatomaceous earth, and chaff).

Due to the suitable $\mathrm{pH}$, water holding capacity, chemical composition (Table 1), and adsorption capacity, GGR is recommended as anew packing material for biofiltration.
TABLE 2: Comparison between adsorption capacities of different adsorbents.

\begin{tabular}{lcccccc}
\hline Adsorbents & $\begin{array}{c}\text { GAC } \\
{[11]}\end{array}$ & $\begin{array}{c}\text { diatomaceous } \\
\text { earth [20] }\end{array}$ & $\begin{array}{c}\text { Compost } \\
{[20]}\end{array}$ & $\begin{array}{c}\text { Chaff } \\
{[20]}\end{array}$ & $\begin{array}{c}\text { GTR } \\
{[11]}\end{array}$ & GGR \\
\hline $\begin{array}{l}\text { Adsorption } \\
\text { capacity } \\
(\mathrm{mg} / \mathrm{g})\end{array}$ & 10.62 & 2.00 & 1.43 & 0.89 & 0.398 & 2.2 \\
\hline
\end{tabular}

3.3.1. The Adsorption Kinetics. Adsorption kinetic models can be helpful to specify the effectiveness of a sorbent in the removing pollutants and to determine the sorption mechanism type. The experimental data of toluene adsorption by GGR were analyzed via two common kinetic models including pseudo-first-order and pseudo-second-order models. The pseudo-first-order kinetic model is shown by

$$
\ln \left(q_{e}-q_{t}\right)=\ln q_{e}-k_{1} t
$$

where $q_{e}(\mathrm{mg} / \mathrm{g})$ and $q_{t}(\mathrm{mg} / \mathrm{g})$ are the quantity of toluene adsorbed onto GGR at equilibrium and at time $(t)$, respectively. $k_{1}(1 / \mathrm{h})$ is the pseudo-first-order rate constant. $k_{1}$ and $q_{e}$ were calculated from the slope and intercept of the straight plotting $\ln \left(q_{e}-q_{t}\right)$ versus $t$, respectively [8].

The data obtained were also fitted by pseudo-secondorder model. This adsorption kinetic can be correlated by [33]

$$
\frac{t}{q_{t}}=\frac{1}{k_{2} q_{e}^{2}}+\frac{t}{q_{e}}
$$

At the beginning stage of the adsorption, because $t$ is nearly equal to zero, the initial adsorption rate, $h(\mathrm{~g} / \mathrm{mg} \cdot \mathrm{h})$, could be represented by

$$
h=k_{2} q_{e}^{2}
$$

where $q_{e}$ and $q_{t}$ are the same as the pseudo-first-order model. $k_{2}$ (g/mg.h) is the pseudo-second-order rate constant. $k_{2}$ and $q_{e}$ are obtained from the intercept and slope of $t / q_{t}$ against $t$ (see (3)), respectively [33].

The pseudo-second-order kinetic model for the removal of toluene vapor by GGR is presented by Figure 2(b). As shown, the higher correlation coefficient $\left(R^{2}=0.996\right)$ acquired by this model with respect to the pseudo-first kinetic model $\left(R^{2}=0.919\right)$ indicated that this model fitted the adsorption data better than the other kinetic models. Moreover, the calculated $q_{e \text {,cal }}(2.36 \mathrm{mg} / \mathrm{g})$ through this kinetic model is rationally closer to experimental $q_{e, \exp }(2.22 \mathrm{mg} / \mathrm{g})$ (Table 3).

3.4. The Effect of Adsorbate Concentration. The effect of initial toluene concentration in the range of 0.86 to $13.86 \mathrm{mg} / \mathrm{L}$ is presented in Figure 3(a). As it can be observed, the GGR is saturated more rapidly as the toluene concentration in the polluted air was increased. This may be due to rising of the driving force of toluene such as van der Waal's forces taking place at higher concentration of the pollutant.

3.4.1. Adsorption Isotherms. Three adsorption isotherm models, Langmuir, Freundlich, and Dubinin-Radushkevich 


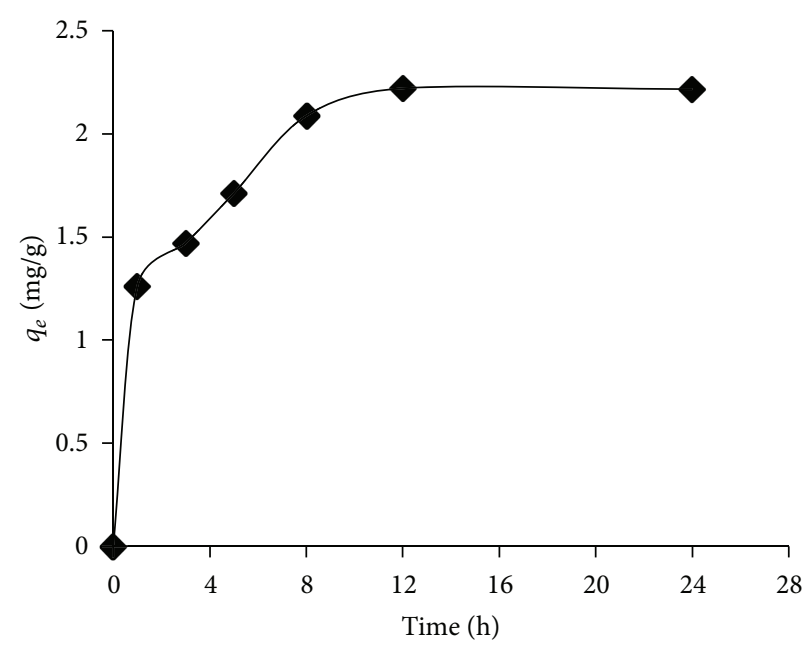

(a)

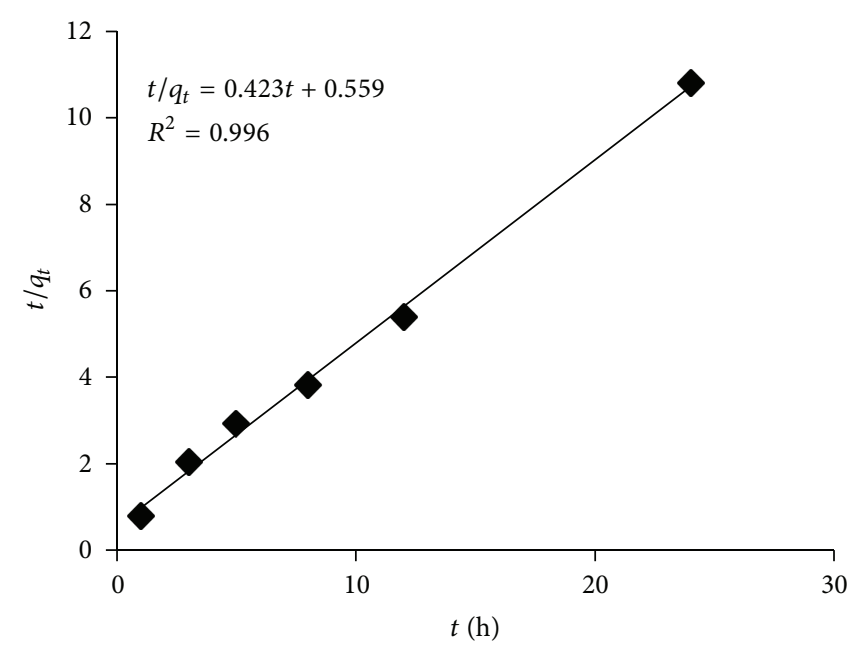

(b)

FIGURE 2: (a) The effect of contact time on the removal of toluene by GGR (adsorbent dose $=0.6 \mathrm{~g}$, temperature $=25^{\circ} \mathrm{C}$, adsorbent humidity $=50 \%$, and adsorbate conc. $=6.928 \mathrm{mg} / \mathrm{L}$ ). (b) Pseudo-second-order kinetic model.

TABLE 3: Parameters of pseudo-second-order kinetic model obtained from this study.

\begin{tabular}{lccccc}
\hline \multirow{2}{*}{ Adsorbate } & $q_{e, \text { experimental }}(\mathrm{mg} / \mathrm{g})$ & \multicolumn{3}{c}{ Pseudo-second-order model } \\
& 2.22 & $k_{2}(\mathrm{~g} / \mathrm{mg} \cdot \mathrm{h})$ & $h(\mathrm{~g} / \mathrm{mg} \cdot \mathrm{h})$ & $q_{e, \text { calculated }}(\mathrm{mg} / \mathrm{g})$ & 2.36 \\
\hline Toluene & 0.29 & 1.67 & $\mathbf{0 . 9 9 6}$ \\
\hline
\end{tabular}

TABLE 4: Langmuir, Freundlich, and D-R isotherm parameters for the adsorption of toluene onto GGR.

\begin{tabular}{lcccccccrr}
\hline \multirow{2}{*}{ Adsorbate } & \multicolumn{3}{c}{ Langmuir isotherm } & \multicolumn{3}{c}{ Freundlich isotherm } & \multicolumn{3}{c}{ D-R isotherm } \\
& $Q_{m}(\mathrm{mg} / \mathrm{g})$ & $b(\mathrm{~L} / \mathrm{mg})$ & $R^{2}$ & $k_{f}$ & $n$ & $R^{2}$ & $q_{m}(\mathrm{mg} / \mathrm{g})$ & $E(\mathrm{~kJ} / \mathrm{mol})$ & $R^{2}$ \\
\hline Toluene & 3.76 & 0.18 & 0.724 & 0.94 & 1.04 & $\mathbf{0 . 9 9 2}$ & 3.14 & 1.38 & 0.887 \\
\hline
\end{tabular}

(D-R), were applied to analyze a relation between toluene concentration and the amounts of toluene adsorbed onto GGR.

The Langmuir isotherm forecasts the maximum monolayer adsorption capacity of the adsorbent [34]. The isotherm is shown by

$$
\frac{C_{e}}{q_{e}}=\frac{C_{e}}{Q_{m}}+\frac{1}{b Q_{m}},
$$

where $C_{e}(\mathrm{mg} / \mathrm{L})$ and $q_{e}(\mathrm{mg} / \mathrm{g})$ are the pollutant concentration and the adsorption capacity of the sorbent at equilibrium time, respectively. $b(\mathrm{~L} / \mathrm{mg})$ is the Langmuir constant and $Q_{m}(\mathrm{mg} / \mathrm{g})$ is the maximum sorbent capacity. $Q_{m}$ and $b$ are calculated by the intercept and slope of the plot of $C_{e} / q_{e}$ against $C_{e}$, respectively [34].

The Freundlich isotherm model was employed for multilayer adsorption on a nonuniform adsorbent surface [35]. This isotherm model can be described by

$$
\ln q_{e}=\ln k_{f}+\frac{1}{n} \ln C_{e},
$$

where $k_{f}(\mathrm{~L} / \mathrm{g})$ and $n$ are the isotherm constants. $k_{f}$ and $n$ are obtained from the intercept and slope of plotting $\ln q_{e}$ versus $\ln C_{e}$ (Figure 3(b)), respectively [35].
The isotherm parameters are presented in Table 4. The Freundlich isotherm model described the adsorption of toluene onto GGR very well $\left(R^{2}=0.992\right)$. Oh et al. (2009) showed that the adsorption of toluene vapors by wet compost, and ground tire rubber was modeled well by Freundlich isotherm [11]. The strong bond between pollutant and adsorbent occurs when the $n$ value obtained from the Freundlich isotherm is more than 1 [8]. Thus, the $n$ value of 1.04 achieved by this isotherm model suggested that toluene vapor is properly adsorbed by the adsorbent. Singh et al. (2010) reported that $n$ value, obtained from Freundlich isotherm of toluene vapor removal with wood charcoal, was 0.73 [1]. The strength of adsorption bond between adsorbate and adsorbent ( $n$ value) obtained by Singh et al. (2010) is weaker than that of our study. Oh et al. (2009) also revealed that the $n$ value obtained for the sorption of toluene via wet compost and ground tire rubber was in the range of $0.96-1.13$ [11].

The Dubinin-Radushkevich isotherm (D-R) specifies that the type of adsorption process is chemical or physical in nature [36]. The D-R isotherm can be described as

$$
\ln q_{e}=\ln q_{m}-\beta \varepsilon^{2}
$$




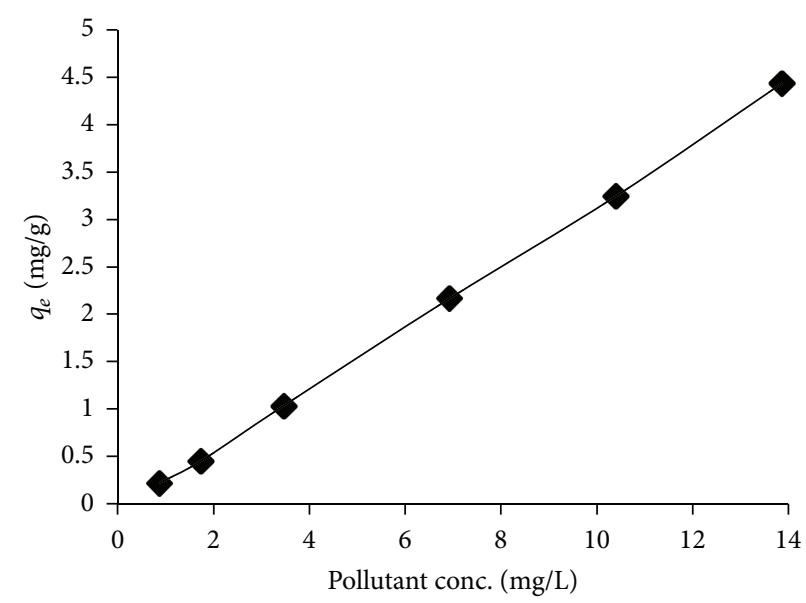

(a)

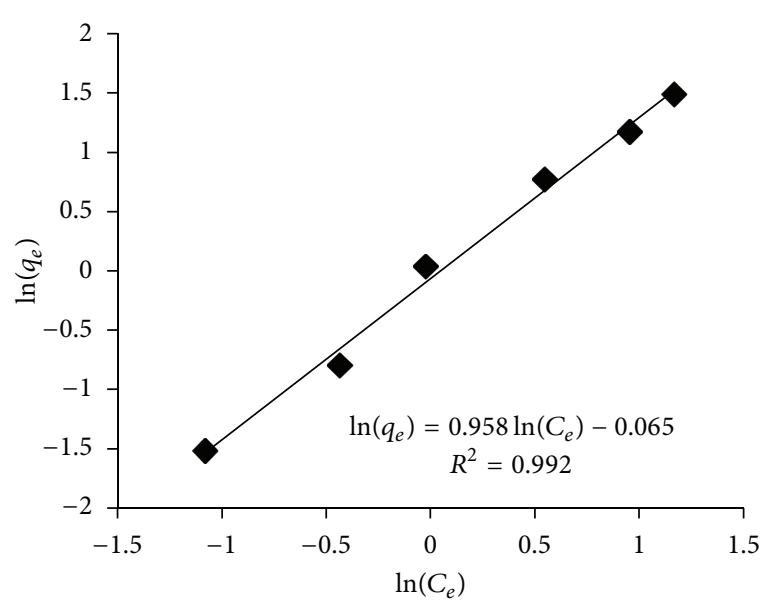

(b)

FIGURE 3: (a) The effect of toluene concentration on the adsorption by GGR (adsorbent dose $=0.6 \mathrm{~g}$, temperature $=25^{\circ} \mathrm{C}$, adsorbent humidity $=50 \%$, and adsorbate Conc. $=0.86$ to $13.86 \mathrm{mg} / \mathrm{L}$ ). (b) Freundlich isotherm model.

TABLE 5: Thermodynamic parameters for the adsorption of toluene by GGR.

\begin{tabular}{ccccccccc}
\hline & \multicolumn{4}{c}{$\Delta \mathrm{G}(\mathrm{kJ} / \mathrm{mol})$} & \multicolumn{3}{c}{$\Delta H(\mathrm{~kJ} / \mathrm{mol})$} & $\Delta S(\mathrm{~J} / \mathrm{mol} \cdot \mathrm{K})$ \\
\hline Toluene & $283 \mathrm{~K}$ & $293 \mathrm{~K}$ & $298 \mathrm{~K}$ & $303 \mathrm{~K}$ & $313 \mathrm{~K}$ & $323 \mathrm{~K}$ & & -150.48 \\
\hline
\end{tabular}

where $q_{m}(\mathrm{mg} / \mathrm{g})$ is the theoretical saturation sorption capacity, $\beta(\mathrm{kJ} / \mathrm{mol})$ is indicated as mean adsorption energy, and $\varepsilon$ (Polanyi Potential) is equal to $R T \ln \left(1+1 / C_{e}\right) \cdot R(\mathrm{~kJ} / \mathrm{mol} \cdot \mathrm{K})$ is the universal gas constant and $T(\mathrm{~K})$ is the temperature. $q_{m}$ and $\beta$ are determined by the intercept and the slope of plot of $\ln q_{e}$ versus $\varepsilon^{2}$, respectively [36].

The type of adsorption process is specified by the $E$ value. $E(\mathrm{~kJ} / \mathrm{mol})$ is the mean adsorption energy that is given by

$$
E=\frac{1}{\sqrt{2 \beta}} .
$$

The $E$ value in the range of $8-16 \mathrm{~kJ} / \mathrm{mol}$ indicates that the chemical ion exchange occurs. $E<8 \mathrm{~kJ} / \mathrm{mol}$ indicates physical and $E>16 \mathrm{~kJ} / \mathrm{mol}$ chemical sorption process [34].

Table 4 shows that the $E$ value of toluene adsorption by GGR is equal to $1.38 \mathrm{~kJ} / \mathrm{mol}$. Therefore, the adsorption of toluene by GGR was identified as physical in nature.

3.5. The Effect of Temperature. The effect of temperature in the range of $10-50^{\circ} \mathrm{C}$ on the adsorption of toluene vapor by GGR was investigated. Equations (9)-(12) were used for the determination of thermodynamic parameters such as enthalpy $(\Delta H)$, Gibbs-free energy $(\Delta G)$, and entropy $(\Delta S)[8]$ :

$$
\begin{gathered}
\Delta G=-R T \ln k, \\
k=\frac{q_{e}}{C_{e}}, \\
\Delta G=\Delta H-T \Delta S,
\end{gathered}
$$

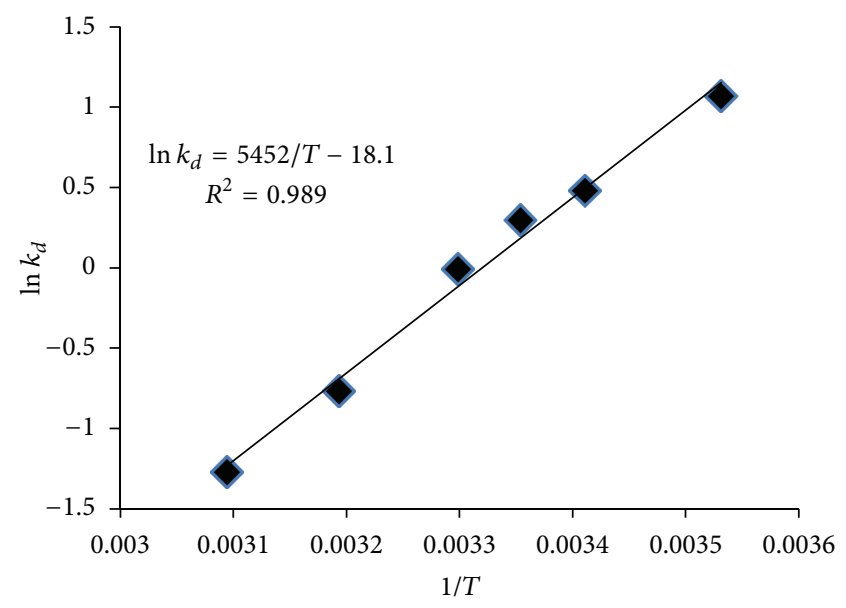

FIGURE 4: The effect of temperature of media on the sorption of toluene (adsorbent dose $=0.6 \mathrm{~g}$, humidity $=50 \%$, contact time $=12 \mathrm{~h}$, and adsorbate conc. $=6.928 \mathrm{mg} / \mathrm{L}$ ).

$$
\ln k=\frac{\Delta S}{R}-\frac{\Delta H}{R T}
$$

where $k$ is the equilibrium constant and $C_{e}, q_{e}$, and $R$ are the same as defined before. The $\Delta S(\mathrm{~J} / \mathrm{mol} \cdot \mathrm{K})$ and $\Delta H(\mathrm{~kJ} / \mathrm{mol})$ of the toluene sorption were calculated from the intercept and slope of the straight plotting $\ln k$ against $1 / T$ (see (12)), respectively [8].

The effect of temperature on the adsorption is shown in Figure 4 and the thermodynamic parameters are presented in Table 5. According to Figure 4, the amount of toluene adsorption was reduced by increasing the temperature. The 
negative values of $\Delta G$ in the temperature range of $10-$ $25^{\circ} \mathrm{C}$ (Table 5) suggested that the adsorption process was spontaneous and feasible, but its positive values indicated that the sorption was not favorable at the temperature of $30-50^{\circ} \mathrm{C}$ [33]. The reduction in the $\Delta G$ value by increasing temperature also indicated that the adsorption is not proper at higher temperatures [37]. Typically, the physical and chemical adsorption occurs while $\Delta G$ is between -20 to $0 \mathrm{~kJ} / \mathrm{mol}$ and -40 to $-400 \mathrm{~kJ} / \mathrm{mol}$, respectively [37]. The value of the $\Delta G$ obtained in this study demonstrated that the uptake of toluene by GGR is physical adsorption as it was found by $\mathrm{D}-\mathrm{R}$ isotherm earlier. The negative value of adsorption enthalpy $(\Delta H)$ also supports that the adsorption process is exothermic in nature [37]. The comparisons between the toluene adsorption capacities at the various temperatures confirm this fact (Figure 4). The entropy change of toluene onto GGR was $-150.48 \mathrm{~J} / \mathrm{mol} \cdot \mathrm{K}$. The negative value of $\Delta S$ indicated a reduction in the liberation of adsorbed toluene on GGR [38].

\section{Conclusion}

In this study, Glycyrrhiza glabra root (GGR) waste was used as a novel adsorbent for the adsorption of toluene vapor from gaseous media. The effect of different conditions including contact time, adsorbate concentration, humidity, and temperature on the adsorption was investigated. The pseudo-second-order kinetic model and Freundlich model fitted the adsorption data better than other kinetic and isotherm models, respectively. The D-R isotherm also showed that the sorption by GGR is physical in nature. The results of the thermodynamic analysis (negative value of obtained $\Delta H)$ corroborate that this adsorption process is exothermic. This adsorbent is a waste material with a sorption capacity of $2.2 \mathrm{mg} / \mathrm{g}$. In comparison with other natural sorbents (e.g., compost, diatomaceous earth, and chaff), GGR seems to be a cost-effective sorbent in the removal of toluene vapor.

\section{Conflict of Interests}

The authors declare that there is no conflict of interests.

\section{Acknowledgment}

This paper is partially the result of $\mathrm{PhD}$ thesis approved in the Isfahan University of Medical Sciences (IUMS). The authors wish to acknowledge Vice Chancellery of Research of IUMS for the financial support, Research Project, no. 390252.

\section{References}

[1] K. Singh, R. S. Singh, B. N. Rai, and S. N. Upadhyay, "Biofiltration of toluene using wood charcoal as the biofilter media," Bioresource Technology, vol. 101, no. 11, pp. 3947-3951, 2010.

[2] A. K. Mathur, C. B. Majumder, and S. Chatterjee, "Combined removal of BTEX in air stream by using mixture of sugar cane bagasse, compost and GAC as biofilter media," Journal of Hazardous Materials, vol. 148, no. 1-2, pp. 64-74, 2007.
[3] M. Farhadian, C. Vachelard, D. Duchez, and C. Larroche, "In situ bioremediation of monoaromatic pollutants in groundwater: a review," Bioresource Technology, vol. 99, no. 13, pp. 52965308, 2008.

[4] S. M. Zamir, R. Halladj, and B. Nasernejad, "Removal of toluene vapors using a fungal biofilter under intermittent loading," Process Safety and Environmental Protection, vol. 89, no. 1, pp. 8-14, 2011.

[5] F. Su, C. Lu, and S. Hu, "Adsorption of benzene, toluene, ethylbenzene and p-xylene by $\mathrm{NaOCl}$-oxidized carbon nanotubes," Colloids and Surfaces A, vol. 353, no. 1, pp. 83-91, 2010.

[6] B. Bina, M. M. Amin, A. Rashidi, and H. Pourzamani, "Benzene and toluene removal by carbon nanotubes from aqueous solution," Archives of Environmental Protection, vol. 38, no. 1, pp. 325, 2012.

[7] Y. J. Tham, P. A. Latif, A. M. Abdullah, A. Shamala-Devi, and Y. H. Taufiq-Yap, "Performances of toluene removal by activated carbon derived from durian shell," Bioresource Technology, vol. 102, no. 2, pp. 724-728, 2011.

[8] H. Nourmoradi, M. Nikaeen, and M. H. Nejad, "Removal of benzene, toluene, ethylbenzene and xylene (BTEX) from aqueous solutions by montmorillonite modified with nonionic surfactant: equilibrium, kinetic and thermodynamic study," Chemical Engineering Journal, vol. 191, pp. 341-348, 2012.

[9] C. Yang, H. Chen, G. Zeng, G. Yu, and S. Luo, "Biomass accumulation and control strategies in gas biofiltration," Biotechnology Advances, vol. 28, no. 4, pp. 531-540, 2010.

[10] S. H. Lin and C. Y. Huang, "Adsorption of BTEX from aqueous solution by macroreticular resins," Journal of Hazardous Materials, vol. 70, no. 1-2, pp. 21-37, 1999.

[11] D. I. Oh, J. H. Song, S. J. Hwang, and J. Y. Kim, "Effects of adsorptive properties of biofilter packing materials on toluene removal," Journal of Hazardous Materials, vol.170, no. 1, pp. 144150, 2009.

[12] R. S. Singh, S. S. Agnihotri, and S. N. Upadhyay, "Removal of toluene vapour using agro-waste as biofilter media," Bioresource Technology, vol. 97, no. 18, pp. 2296-2301, 2006.

[13] A. R. Pedersen and E. Arvin, "Removal of toluene in waste gases using a biological trickling filter," Biodegradation, vol. 6, no. 2, pp. 109-118, 1995.

[14] S. Standeker, Z. Novak, and Z. Knez, "Removal of BTEX vapours from waste gas streams using silica aerogels of different hydrophobicity," Journal of Hazardous Materials, vol. 165, no. 13, pp. 1114-1118, 2009.

[15] W. Zhang, Z. Qu, X. Li, Y. Wang, D. Ma, and J. Wu, “Comparison of dynamic adsorption/desorption characteristics of toluene on different porous materials," Journal of Environmental Sciences, vol. 24, no. 3, pp. 520-528, 2012.

[16] H. Chen, H. Zhang, and Y. Yan, "Preparation and characterization of a novel gradient porous ZSM-5 zeolite membrane/PSSF composite and its application for toluene adsorption," Chemical Engineering Journal, vol. 209, pp. 372-378, 2012.

[17] D. G. Lee, J. H. Kim, and C. H. Lee, "Adsorption and thermal regeneration of acetone and toluene vapors in dealuminated $\mathrm{Y}$ zeolite bed," Separation and Purification Technology, vol. 77, no. 3, pp. 312-324, 2011.

[18] R. I. Slioor, J. M. Kanervo, T. J. Keskitalo, and A. O. I. Krause, "Gas phase adsorption and desorption kinetics of toluene on $\mathrm{Ni} / \gamma-\mathrm{Al}_{2} \mathrm{O}_{3}$," Applied Catalysis A, vol. 344, no. 1-2, pp. 183-190, 2008. 
[19] T. Agelakopoulou and F. Roubani-Kalantzopoulou, "Chromatographic analysis of adsorption: chemisorption and/or physisorption," Chromatographia, vol. 69, no. 3-4, pp. 243-255, 2009.

[20] S. Mudliar, B. Giri, K. Padoley et al., "Bioreactors for treatment of VOCs and odours-a review," Journal of Environmental Management, vol. 91, no. 5, pp. 1039-1054, 2010.

[21] M. A. Lillo-Ródenas, A. J. Fletcher, K. M. Thomas, D. CazorlaAmorós, and A. Linares-Solano, "Competitive adsorption of a benzene-toluene mixture on activated carbons at low concentration," Carbon, vol. 44, no. 8, pp. 1455-1463, 2006.

[22] J. Pei and J. S. Zhang, "Determination of adsorption isotherm and diffusion coefficient of toluene on activated carbon at low concentrations," Building and Environment, vol. 48, pp. 66-76, 2012.

[23] K. D. Kim, E. J. Park, H. O. Seo, M. G. Jeong, Y. D. Kim, and D. C. Lim, "Effect of thin hydrophobic films for toluene adsorption and desorption behavior on activated carbon fiber under dry and humid conditions," Chemical Engineering Journal, vol. 200202, pp. 133-139, 2012.

[24] M. Takeuchi, M. Hidaka, and M. Anpo, "Efficient removal of toluene and benzene in gas phase by the $\mathrm{TiO}_{2} / \mathrm{Y}$-zeolite hybrid photocatalyst," Journal of Hazardous Materials, vol. 237-238, pp. 133-139, 2012.

[25] J. Y. San, Y. C. Hsu, and L. J. Wu, "Adsorption of toluene on activated carbon in a packed bed," International Journal of Heat and Mass Transfer, vol. 41, no. 21, pp. 3229-3238, 1998.

[26] A. Rochereau, B. Marc, L. C. Laurence, E. Mauret, S. Albert, and L. C. Pierre, "Combined air treatment: effect of composition of fibrous filters on toluene adsorption and particle filtration efficiency," Chemical Engineering Research and Design, vol. 86, no. 6, pp. 577-584, 2008.

[27] V. K. Gupta, A. Fatima, U. Faridi et al., "Antimicrobial potential of Glycyrrhiza glabra roots," Journal of Ethnopharmacology, vol. 116, no. 2, pp. 377-380, 2008.

[28] N. P. Visavadiya and A. V. R. L. Narasimhacharya, "Hypocholesterolaemic and antioxidant effects of Glycyrrhiza glabra (Linn) in rats," Molecular Nutrition \& Food Research, vol. 50, no. 11, pp. 1080-1086, 2006.

[29] B. Ovez, S. Ozgen, and M. Yuksel, "Biological denitrification in drinking water using Glycyrrhiza glabra and Arunda donax as the carbon source," Process Biochemistry, vol. 41, no. 7, pp. 1539$1544,2006$.

[30] H. K. Ahn, T. L. Richard, and T. D. Glanville, "Laboratory determination of compost physical parameters for modeling of airflow characteristics," Waste Management, vol. 28, no. 3, pp. 660-670, 2008.

[31] J. P. A. Lodge, Methods of Air Sampling and Analysis, CRC, 1988.

[32] M. E. Acuña, F. Pérez, R. Auria, and S. Revah, "Microbiological and kinetic aspects of a biofilter for the removal of toluene from waste gases," Biotechnology and Bioengineering, vol. 63, no. 2, pp. $175-184,2000$.

[33] H. B. Senturk, D. Ozdes, A. Gundogdu, C. Duran, and M. Soylak, "Removal of phenol from aqueous solutions by adsorption onto organomodified Tirebolu bentonite: equilibrium, kinetic and thermodynamic study," Journal of Hazardous Materials, vol. 172, no. 1, pp. 353-362, 2009.

[34] H. Faghihian, H. Nourmoradi, and M. Shokouhi, "Performance of silica aerogels modified with amino functional groups in PB, (II) and CD, (II) removal from aqueous solutions," Polish Journal of Chemical Technology, vol. 14, no. 1, pp. 50-56, 2012.
[35] H. Koyuncu, N. Yıldız, U. Salgın, F. Köroğlu, and A. Çalımlı, "Adsorption of $o$-, $m$-and $p$-nitrophenols onto organically modified bentonites," Journal of Hazardous Materials, vol. 185, no. 2-3, pp. 1332-1339, 2011.

[36] A. R. Kul and H. Koyuncu, "Adsorption of $\mathrm{Pb}$ (II) ions from aqueous solution by native and activated bentonite: kinetic, equilibrium and thermodynamic study," Journal of Hazardous Materials, vol. 179, no. 1-3, pp. 332-339, 2010.

[37] J. Su, H. F. Lin, Q. P. Wang, Z. M. Xie, and Z. L. Chen, "Adsorption of phenol from aqueous solutions by organomontmorillonite," Desalination, vol. 269, no. 1-3, pp. 163-169, 2011.

[38] H. Nourmoradi, M. Khiadani, and M. Nikaeen, "Multi-component adsorption of benzene, toluene, ethylbenzene, and xylene from aqueous solutions by montmorillonite modified with tetradecyl trimethyl ammonium bromide," Journal of Chemistry, vol. 2013, Article ID 589354, 10 pages, 2013. 


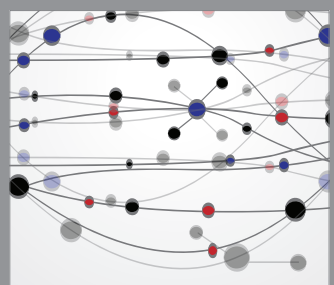

The Scientific World Journal
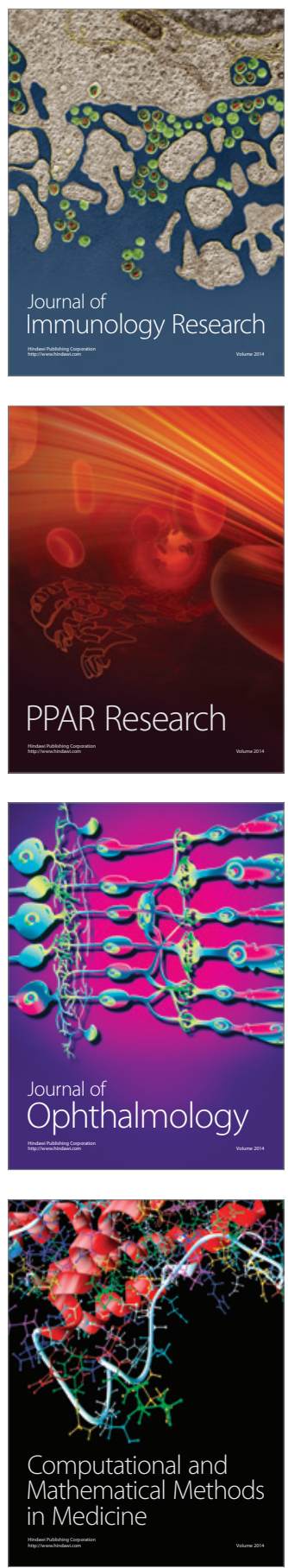

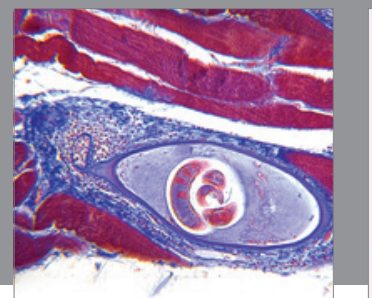

Gastroenterology

Research and Practice
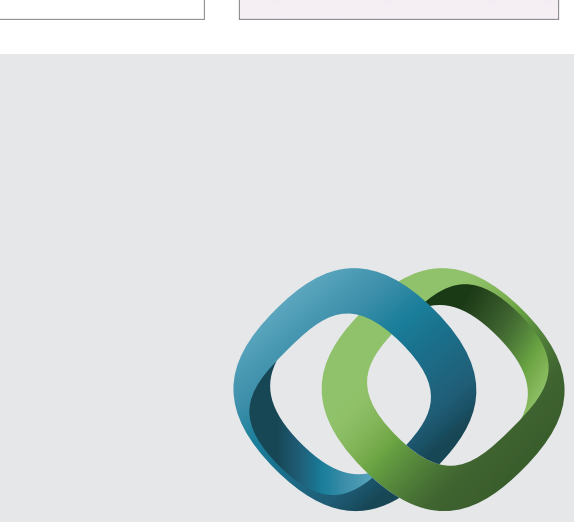

\section{Hindawi}

Submit your manuscripts at

http://www.hindawi.com
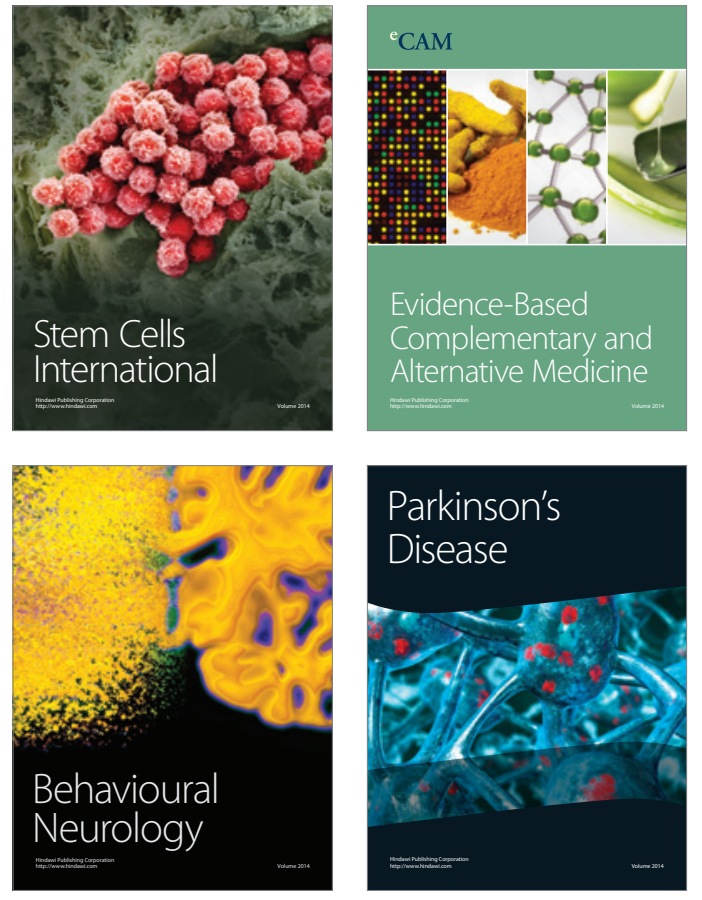
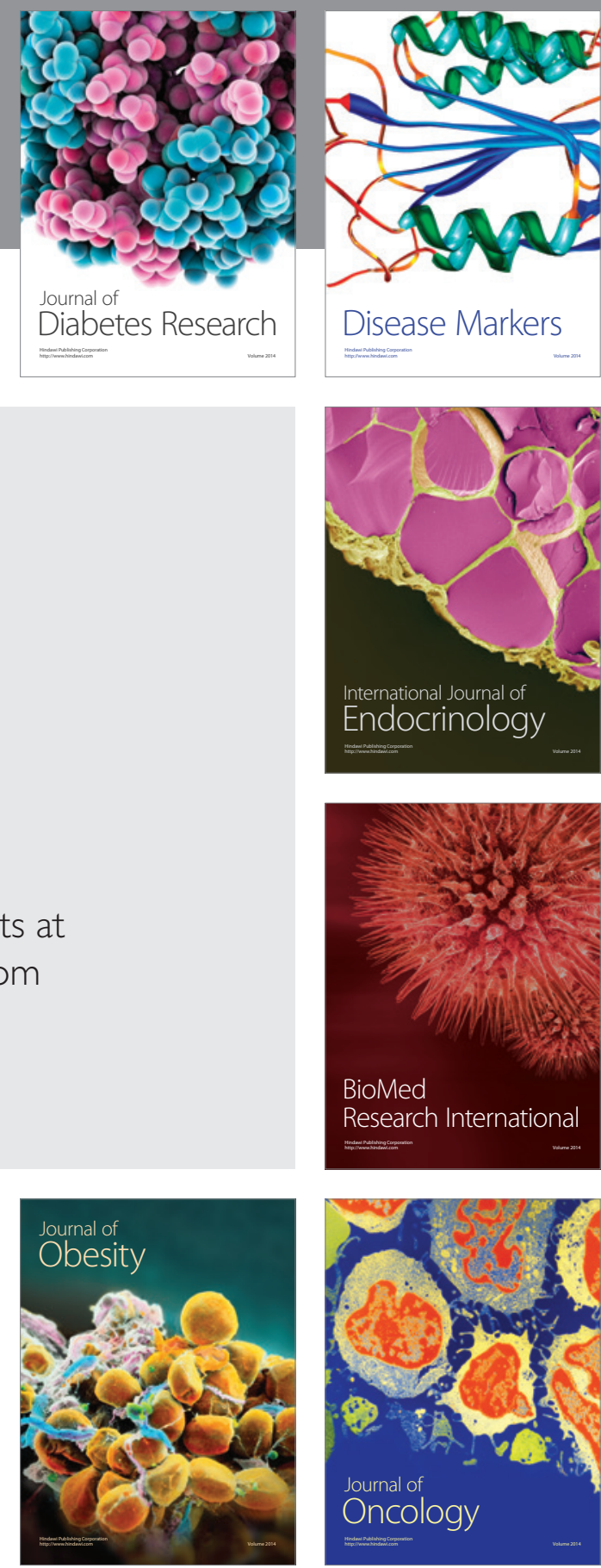

Disease Markers
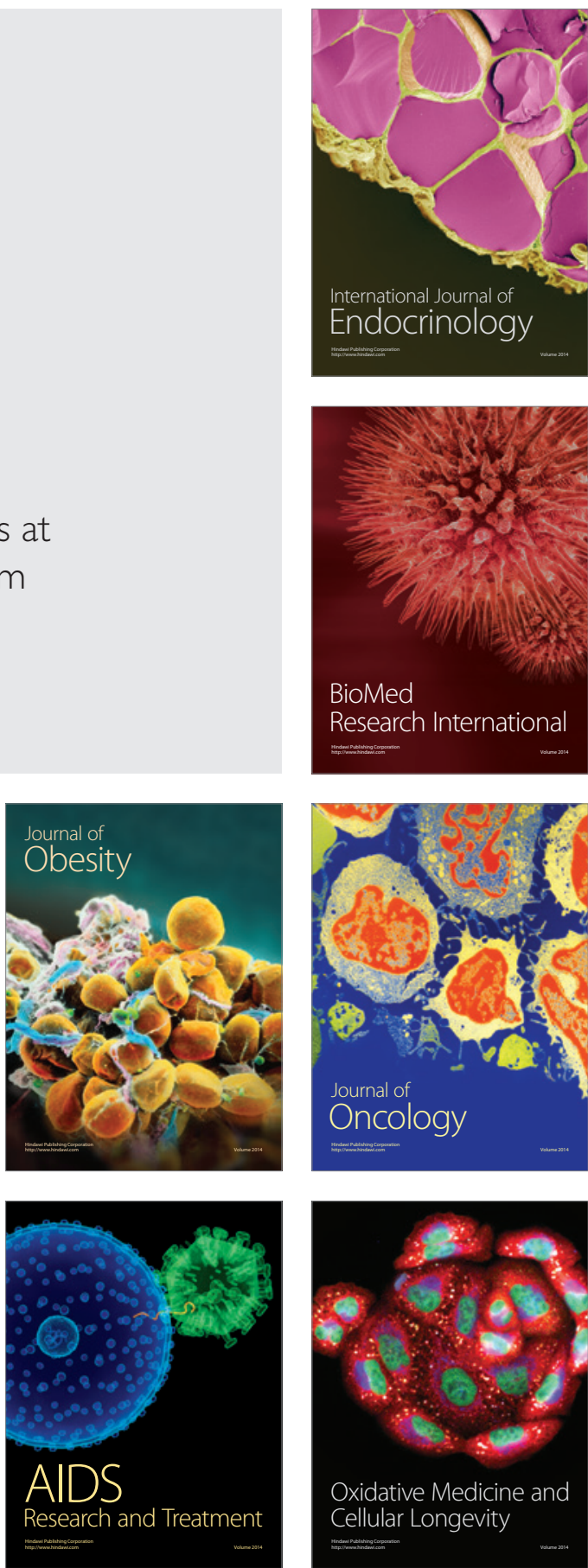